\section{Commentary: Sleeve lobectomy for centrally located non-small cell lung cancer: Should the approach be a matter of debate?}

\author{
Arthur Vieira, MD, and Paula A. Ugalde, MD
}

A groundbreaking manuscript from Deslauriers and colleagues $^{1}$ established sleeve lobectomy, rather than pneumonectomy, as the ideal surgical treatment for centrally located non-small cell lung cancer (NSCLC). In this work, patients with NSCLC underwent sleeve lobectomy via an open approach with low operative mortality, morbidity, and excellent oncologic outcomes. It is one of the largest cohorts published to date.

Over the last 20 years, video-assisted thoracoscopic surgery (VATS) for lung resection became the standard approach for the treatment of early-stage lung cancer due to better pain control, faster return to daily activities, and reduced length of hospital stay and chest tube insertion as compared with open surgery. ${ }^{2-5}$ Currently, there is a great interest in robotic surgery due to its improved ergonomics, better imaging, increased range of movement, and gentler learning curve as compared with VATS. ${ }^{6-8}$ At high-volume centers, as surgeons gain experience with VATS and robotic surgery, more challenging cases are managed with these minimally invasive approaches. This reflects the natural instinct of the thoracic surgeon to push the limits of surgical technology without compromising safety and the quality of the oncologic resection.

In the current issue of Journal, Qiu and colleagues ${ }^{9}$ present their experience with sleeve lobectomy in 188 patients with NSCLC over a 5-year period (2012-2017): 66 by open thoracotomy, 73 by VATS, and 49 by robotic thoracoscopic surgery. Using matching weights, they found an overall 90 -day mortality of $2.1 \%$ and overall morbidity of $26.6 \%$, with no statistically significant differences

\footnotetext{
From the Department of Thoracic Surgery, Institut Universitaire de Pneumologie et Cardiologie de Quebec, Quebec, Quebec, Canada.

Disclosures: Authors have nothing to disclose with regard to commercial support.

Received for publication Nov 8, 2019; accepted for publication Nov 12, 2019; available ahead of print Nov 30, 2019

Address for reprints: Paula A. Ugalde, MD, Institut Universitaire de Cardiologie et de Pneumologie de Québec, 2725, chemin Sainte-Foy Québec, Quebec, Quebec G1V4G5, Canada (E-mail: paula.ugalde@ criucpq.ulaval.ca).

J Thorac Cardiovasc Surg 2020;160:851-2

0022-5223/\$36.00

Copyright (C) 2019 by The American Association for Thoracic Surgery

http://dx.doi.org/10.1016/j.jtcvs.2019.11.053
}

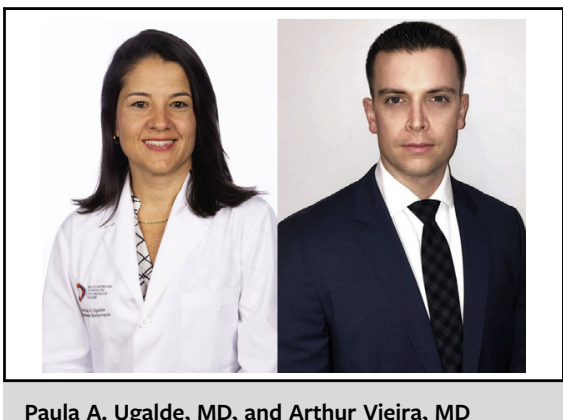

Paula A. Ugalde, MD, and Arthur Vieira, MD

$$
\begin{aligned}
& \text { CENTRAL MESSAGE } \\
& \text { Robotic surgery led to the best } \\
& \text { postoperative outcomes after } \\
& \text { sleeve lobectomy when } \\
& \text { compared with VATS and thora- } \\
& \text { cotomy. Robotic platform is a } \\
& \text { valuable surgical tool for cen- } \\
& \text { trally located lung cancers. }
\end{aligned}
$$

between approaches. In pairwise comparisons, the robotic group had lower estimated blood loss, shorter operative time, and shorter duration of chest drainage as compared with the VATS and open groups. Although $8.8 \%$ of VATS group and $1.7 \%$ of the open group had an incomplete resection, all surgical margins were negative in the robotic group ( $0 \%$ incomplete resection). Lymphadenectomy and complications were similar between the 3 groups. When Kaplan-Meier survival curves were examined, no statistically significant differences were found in diseasefree survival when comparing robotic versus VATS or open approaches. Overall survival (OS) after open surgery was inferior to OS survival after robotic surgery (3-year OS: $59.3 \%$ [95\% confidence interval, $0.43-0.72]$ vs $89.7 \%$ [ $95 \%$ confidence interval, 0.75-0.97]; log-rank, adjusted $P=.007)$. No statistically significant differences in OS were observed between the robotic and VATS approaches and between the VATS and open surgery.

The main strength of this study is the high number of patients who underwent sleeve resection. The findings make us wonder whether robotic surgery may be safer than other approaches and offer superior oncologic results to patients with centrally located tumors who undergo sleeve lobectomy. Further study is needed to establish whether robotic sleeve lobectomy leads to superior outcomes. We can at least accept, based on this study and others, that complex procedures such as sleeve lobectomy can be performed minimally invasively with noninferior results to open surgery 
in experienced hands. Because the learning curve for robotic surgery seems gentler than the learning curve for VATS, surgeons might choose to transition from open techniques to robotic surgery without doing VATS. It will be interesting to see how the current generation of surgical trainees chooses to adopt minimally invasive approaches. Although the evidence is weak supporting robotic surgery over other approaches and the cost of the robotic platform is a limitation, the use of robotic surgery is growing exponentially. One way or another, minimally invasive thoracic surgery is here to stay and is rapidly evolving.

\section{References}

1. Deslauriers J, Gregoire J, Jacques LF, Piraux M, Guojin L, Lacasse Y. Sleeve lobectomy versus pneumonectomy for lung cancer: a comparative analysis of survival and sites or recurrences. Ann Thorac Surg. 2004;77:1152-6.

2. National Comprehensive Cancer Network. Non-Small Cell Lung Cancer (Version 1.2020); . Available at: https://www.nccn.org/professionals/physician_gls/ recently_updated.aspx. Accessed November 6, 2019.

3. Postmus PE, Kerr KM, Oudkerk M, Senan S, Waller DA, Vansteenkiste J, et al; on behalf of the ESMO Guidelines Committee. Early and locally advanced non-small-cell lung cancer (NSCLC): ESMO clinical practice guidelines for diagnosis, treatment and follow-up. Ann Oncol. 2017;28:iv1-21.

4. Howington JA, Blum MG, Chang AC, Balekian AA, Murthy SC. Treatment of stage I and II non-small cell lung cancer: diagnosis and management of lung cancer, 3rd ed: American College of Chest Physicians evidence-based clinical practice guidelines. Chest. 2013;143: e278S-313S

5. Lim E, Dunning J, Shackcloth M, Anikin V, Naidu B, Belcher E, et al. In hospital clinical efficacy, safety and oncologic outcomes from VIOLET: a UK multi-centre RCT of VATS versus open lobectomy for lung cancer [abstract]. In: Plenary Session-Presidential Symposium of the IASLC 2019 World Conference on Lung Cancer; September 7-10, 2019; Barcelona, Spain. Abstract ID 1257.

6. Veronesi G, Galetta D, Maisonneuve P, Melfi F, Schmid RA, Borri A, et al. Four-arm robotic lobectomy for the treatment of early-stage lung cancer. J Thorac Cardiovasc Surg. 2010;140:19-25.

7. Cerfolio RJ, Bryant AS, Skylizard L, Minnich DJ. Initial consecutive experience of completely portal robotic pulmonary resection with 4 arms. J Thorac Cardiovasc Surg. 2011;142:740-6.

8. Cerfolio RJ. Robotic sleeve lobectomy: technical details and early results. $J$ Thorac Dis. 2016;8:S223-6.

9. Qiu T, Yandong Z, Yunpeng X, Qin Y, Niu Z, Shen Y, et al. Robotic sleeve lobectomy for centrally located non-small cell lung cancer: a propensity scoreweighted comparison with thoracoscopic and open surgery. J Thorac Cardiovasc Surg. 2020;160:838-46.e2.
See Article page 838.

\section{Commentary: Minimally invasive sleeve lobectomy - from case report curiosity to standard of care?}

\author{
Nirmal K. Veeramachaneni, MD
}

In this issue of the Journal, Qiu and colleagues ${ }^{1}$ report on their experience with 188 patients undergoing sleeve lobectomy from 2012 to 2017 . What is remarkable is the volume of procedures and their ability to transition from thoracotomy, to video-assisted thoracoscopic surgery (VATS), to a robotic platform in a short time frame. For this complex operation, the authors noted a mortality

From the Department of Cardiovascular and Thoracic Surgery, University of Kansas Health System, Kansas City, Kan.

Disclosures: Author has nothing to disclose with regard to commercial support.

Received for publication Nov 4, 2019; revisions received Nov 4, 2019; accepted for publication Nov 4, 2019; available ahead of print Nov 27, 2019.

Address for reprints: Nirmal K. Veeramachaneni, MD, Department of Cardiovascular and Thoracic Surgery, University of Kansas Health System, 4000 Cambridge St,

Kansas City, KS 66160 (E-mail: nveeramachaneni@kumc.edu).

J Thorac Cardiovasc Surg 2020;160:852-3

$0022-5223 / \$ 36.00$

Copyright (C) 2019 by The American Association for Thoracic Surgery

http://dx.doi.org/10.1016/j.jtcvs.2019.11.020
Check for updates

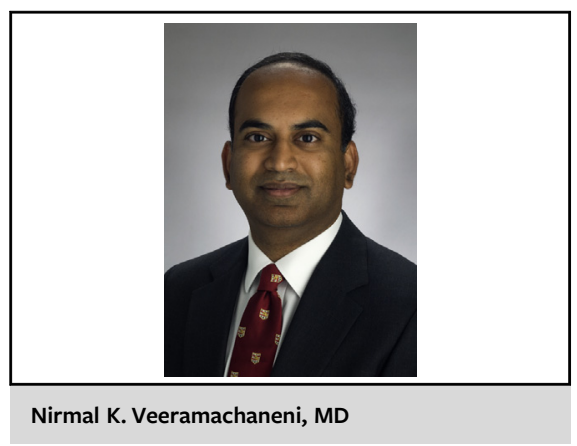

CENTRAL MESSAGE

Robotic and VATS sleeve lobec-

tomy is feasible. Surgeons who

have reported excellent results

have considerable experience

with minimally invasive

techniques.

rate of $2.1 \%$, with no conversions to open surgery in either the VATS or robotic groups, and no difference in complications. Their latest technique used the robot-length of stay, operative time, and blood loss were all least within this group. Given the inherent selection bias and 